\title{
Pulmonary Disability in Coal Workers' Pneumoconiosis
}

\author{
J. P. LYONS， R. RYDER， H. CAMPBELL， J. GOUGH
}

British Medical fournal, 1972, 1, 713-716

\section{Summary}

Results from a correlation survey which compared radiological and physiological findings during life with detailed morbid anatomical findings in the lungs of $\mathbf{2 4 7}$ deceased miners and ex-miners with pneumoconiosis were used to assess the extent and significance of their pulmonary disability.

Coal workers' pneumoconiosis usually caused progressive impairment of ventilation, which in the simple type of disease was not related to radiological category. In such cases the presence of emphysema was found to be a more important factor in determining the impairment of ventilation than the radiological category of simple pneumoconiosis.

\section{Introduction}

Consistent relations between radiological categories and pulmonary disability cannot usually be satisfactorily shown in coal workers' pneumoconiosis, particularly in the earlier stages of the disease. This is one of the major reasons why many authorities consider that simple pneumoconiosis of itself is unlikely to be a cause of significant disability.

Gilson and Hugh Jones (1955) concluded, after comprehensive investigations of lung function in miners in limited age groups, that "simple pneumoconiosis causes only slight increase of breathlessness over that which develops even in normal men as they grow older." Carpenter et al. (1956) and Cochrane et al. (1961) came to broadly similar conclusions after carrying out an extensive survey in the South Wales Rhondda Valley which related ventilatory capacity to radiological appearances. They considered, in addition, that their findings suggested that significant impairment of ventilation due to the disease did not arise in coal workers' pneumoconiosis until the radiological stage of category B progressive massive fibrosis occurred. On the other hand, Rogan et al. (1961) found that impairment of ventilation was related to category of simple pneumoconiosis, and Morgan et al. (1971) found an increased residual volume in working Pennsylvania coal miners with simple pneumoconiosis which was also related to radiological category.

Reduction of the transfer factor has also been reported in certain types of simple pneumoconiosis both from the Continent (Englert and De Coster, 1965) and from Great Britain (Lyons et al., 1967; Cotes et al., 1970). Rasmussen and Nelson (1971) reported results of lung function tests, including studies of both ventilation and gas transfer, in 368 Appalachian soft-coal miners. They found no correlation between the radiological categories of pneumoconiosis and ventilatory function even in miners with progressive massive fibrosis although oxygen transfer was more seriously impaired in the latter subjects. They concluded that disabling respiratory insufficiency often occurred in the absence of radiological evidence of progressive massive fibrosis and

Pneumoconiosis Medical Panel, Cardiff

J. P. LYONS, M.D., T.D.D., Senior Medical Officer

Welsh National School of Medicine, Cardifi

R. RYDER, M.B., B.CH., M.R.C.PATH., Lecturer in Pathology (At present Consultant Pathologist, Merthyr and Aberdare Hospital Group)

H. CAMPBELI, M.B., B.S., Professor of Medical Statistics J. GOUGH, M.D., F.R.C.PATH., Emeritus Professor of Pathology pointed out that meaningful evaluation of respiratory function in pneumoconiosis should include assessment of gas exchange.

The present study relates the ventilatory capacity and the radiological findings to the morbid anatomical changes in each of 247 deceased coal miners. It was designed in the hope that a direct comparison between the physiological and pathological findings in disabled cases would prove more fruitful in explaining the cause of disability in coal workers' pneumoconiosis than radiological and physiological comparisons alone.

\section{Material and Methods}

The material on which the study is based comes from a correlation survey carried out jointly between the Pneumoconiosis Medical Panel, Cardiff, and the university departments of pathology and medical statistics, Welsh National School of Medicine. The method of its collection and investigation has already been given in full detail (Ryder et al., 1970a) so only a brief summary of them is given here together with some additional relevant physiological data.

A population of 247 deceased coal miners and ex-miners, virtually all of whom had suffered from pneumoconiosis during life and all of whom had attended the Cardiff Pneumoconiosis Medical Panel at least once within four years of death, was studied. Detailed contemporary radiological and ventilatory examinations had been carried out during life and these findings were compared with the morbid anatomical findings in the lungs. These included histological and large lung sections, a quantitative estimation of emphysema, and measurement of the Reid (1958) index. The Reid index is the ratio of the thickness of the bronchial mucous gland layer to that part of the bronchial wall measured between the basement membrane of the epithelium and the perichondrium of the bronchial cartilage. The smoking history was available for all of the cases.

\section{Physiology}

Regular measurement of the indirect maximum breathing capacity calculated from the forced expiratory volume in 0.75 second $\left(\mathrm{FEV}_{0.75}\right)$ was introduced at the Cardiff Pneumoconiosis Medical Panel in 1957, and since that time all cases examined have had ventilatory capacity tests performed. In 1960 the $\mathrm{FEV}_{1}$ replaced the $\mathrm{FEV}_{0.75}$ and the forced vital capacity (FVC) was measured in addition, and these two tests have continued in regular use since that time, the Poulton spirometer being used in standardized conditions. As a consequence regular serial measurements of ventilatory capacity were available in most cases over periods ranging from two to nine years for the FEV and from two to six years for the FVC. The table of conversion devised by McKerrow et al. (1960) was used to convert the earlier $\mathrm{FEV}_{0.75}$ to $\mathrm{FEV}_{1}$. Although the $\mathrm{FEV}_{1}$ was measured at the Panel examinations on all 247 of the miners, the FVC was omitted in 20 of them mainly for technical reasons. Similarly the Reid index was available for only 211 of the miners, but these omissions are sufficiently well scattered throughout the various categories and age groups so as not to be a source of bias.

\section{Results}

Table I compares the mean age and ventilatory and morbid anatomical findings in the miners with the final $x$-ray category, 
and Tables II and III contrast the same findings with the final FEV $_{1}$ and the final FEV/FVC. Fig. 1 shows these findings in graphic form.

TABle I-Disability in Coal Miners' Pneumoconiosis. Mean Values of Observations by Final X-ray Category

\begin{tabular}{c|c|c|c|c|c|c}
\hline $\begin{array}{c}\text { Final } X \text {-ray } \\
\text { Category }\end{array}$ & $\begin{array}{c}\text { Mean } \\
\text { Age in } \\
\text { Years }\end{array}$ & $\begin{array}{c}\text { Mean } \\
\text { FEV } \\
(1 .)\end{array}$ & $\begin{array}{c}\text { Mean } \\
\text { FVC } \\
(1 .)\end{array}$ & $\begin{array}{c}\text { Mean } \\
\text { FEV/FVC } \\
(\%)\end{array}$ & $\begin{array}{c}\text { Mean } \\
\text { Emphy- } \\
\text { sema } \\
\text { Count }\end{array}$ & $\begin{array}{c}\text { Mean } \\
\text { Reid } \\
\text { Index }\end{array}$ \\
\hline 0 & 61.4 & 1.56 & 2.55 & 59.5 & 10.8 & 46.5 \\
1 & 60.7 & 1.84 & 2.99 & 58.3 & 10.9 & 42.1 \\
$2+3$ & 62.8 & 1.88 & 2.97 & 62.4 & 7.9 & 44.8 \\
A & 66.3 & 1.80 & 2.90 & 62.4 & 12.0 & 41.9 \\
B & 62.9 & 1.51 & 2.58 & 57.6 & 11.8 & 43.3 \\
C & 61.5 & 1.29 & 2.36 & 55.0 & 10.6 & 47.2 \\
\hline
\end{tabular}

TABLE II-Disability in Coal Miners' Pneumoconiosis. Mean Values of Observations by Final FEV

\begin{tabular}{|c|c|c|c|c|c|c|}
\hline $\begin{array}{l}\text { Final } \\
\text { FEV }_{1}\end{array}$ & $\begin{array}{c}\text { Mean } \\
\text { Age in } \\
\text { Years }\end{array}$ & $\begin{array}{c}\text { Mean } \\
\text { FEV } \\
\text { (1.) }\end{array}$ & $\begin{array}{c}\text { Mean } \\
\text { FVC } \\
\text { (1.) }\end{array}$ & $\underset{\substack{\text { Mean } \\
\text { FEV/FVC }}}{ }$ & $\begin{array}{l}\text { Mean } \\
\text { Emphy- } \\
\text { sema } \\
\text { Count }\end{array}$ & $\begin{array}{l}\text { Mean } \\
\text { Reid } \\
\text { Index }\end{array}$ \\
\hline $\begin{array}{l}0 \cdot 5-0 \cdot 9 \\
1 \cdot 0-1 \cdot 4 \\
1 \cdot 5-1 \cdot 9 \\
2 \cdot 0-2 \cdot 4 \\
2 \cdot 5-2 \cdot 9 \\
3 \cdot 0 \text { and over }\end{array}$ & $\begin{array}{l}62 \cdot 0 \\
64 \cdot 8 \\
65 \cdot 1 \\
62 \cdot 0 \\
59 \cdot 0 \\
51 \cdot 2\end{array}$ & $\begin{array}{l}0.75 \\
1 \cdot 19 \\
1 \cdot 69 \\
2 \cdot 19 \\
2 \cdot 70 \\
3.45\end{array}$ & $\begin{array}{l}1 \cdot 70 \\
2.33 \\
2 \cdot 76 \\
3.32 \\
3.74 \\
4.51\end{array}$ & $\begin{array}{l}45 \cdot 2 \\
52 \cdot 2 \\
62 \cdot 4 \\
66 \cdot 7 \\
72 \cdot 5 \\
75 \cdot 8\end{array}$ & $\begin{array}{r}14 \cdot 8 \\
12.5 \\
11 \cdot 1 \\
8.0 \\
4 \cdot 9 \\
5 \cdot 4\end{array}$ & $\begin{array}{l}43 \cdot 3 \\
45 \cdot 4 \\
45 \cdot 2 \\
44 \cdot 7 \\
39 \cdot 9 \\
37 \cdot 7\end{array}$ \\
\hline
\end{tabular}

TABLE III-Disability in Coal Miners' Pneumoconiosis. Mean Values of Observations by Final FEV|FVC Percentage

\begin{tabular}{|c|c|c|c|c|c|c|}
\hline $\begin{array}{c}\text { Final } \\
\text { FEV/FVC }\end{array}$ & $\begin{array}{r}\text { Mean } \\
\text { Age in } \\
\text { Years }\end{array}$ & $\begin{array}{c}\text { Mean } \\
\text { FEV } \\
\text { (1.) }\end{array}$ & $\begin{array}{l}\text { Mean } \\
\text { FVC } \\
\text { (1.) }\end{array}$ & $\underset{(\%)}{\text { Mean }} \underset{(\% / F V C}{\text { FEV }}$ & $\begin{array}{c}\text { Mean } \\
\text { Emphy- } \\
\text { sema } \\
\text { Count }\end{array}$ & $\begin{array}{l}\text { Mean } \\
\text { Reid } \\
\text { Index }\end{array}$ \\
\hline \multirow{2}{*}{$\begin{array}{c}\text { Less than } \\
40 \% \\
40 \%-49 \% \\
50 \%-59 \% \\
60 \%,-69 \% \\
70 \% \text { and } \\
\text { over }\end{array}$} & $\begin{array}{l}60 \cdot 0 \\
64 \cdot 6 \\
62 \cdot 6 \\
63 \cdot 1\end{array}$ & $\begin{array}{l}0.76 \\
0.99 \\
1.36 \\
1.84\end{array}$ & $\begin{array}{l}2 \cdot 29 \\
2 \cdot 22 \\
2 \cdot 52 \\
2 \cdot 86\end{array}$ & $\begin{array}{l}32 \cdot 7 \\
44 \cdot 0 \\
54 \cdot 1 \\
63 \cdot 8\end{array}$ & $\begin{array}{l}10 \cdot 9 \\
14 \cdot 3 \\
12 \cdot 0 \\
11 \cdot 7\end{array}$ & $\begin{array}{l}43 \cdot 0 \\
43 \cdot 9 \\
45 \cdot 2 \\
45 \cdot 4\end{array}$ \\
\hline & $60 \cdot 7$ & 2.39 & 3.22 & 75.9 & $5 \cdot 7$ & $41 \cdot 3$ \\
\hline
\end{tabular}

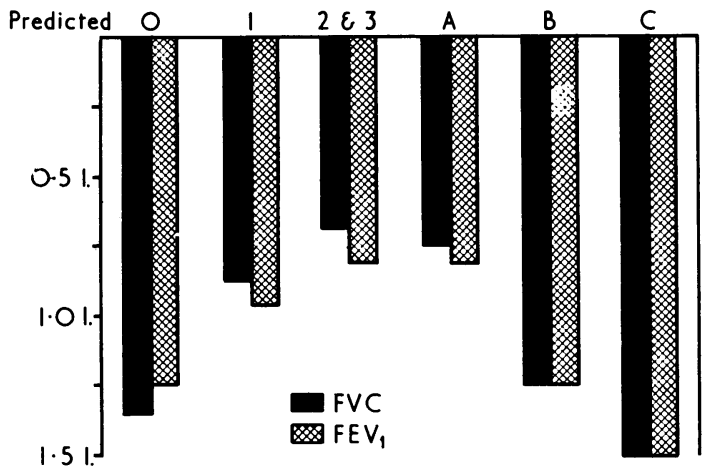

FIG. 1-Reduction below normal value for $\mathrm{FEV}_{1}$ and $\mathrm{FVC}$ by radiological category.

It is clear from these tables and figure that although all the aspects of ventilatory function are reduced below normal values according to Cotes (1965), these reductions are not related to the category of simple pneumoconiosis. The pattern which we found for $\mathrm{FEV}_{1}$ agrees closely with those found by Carpenter et al. (1956) and Cochrane et al. (1961) in the Rhondda except that our cases are more disabled. The findings in respect of FVC and FEV/FVC suggest that the impairment of ventilation present is of obstructive rather than the restrictive type which might be expected if coal workers' pneumoconiosis were a purely fibrotic disease. It is probable that the presence of the excess emphysema in the pneumoconiosis cases, shown in our earlier paper, is at least partially responsible for this, which suggests that it is an integral and significant part of the disease.

Table IV contrasts the ventilatory and morbid anatomical findings with the final $x$-ray type of pneumoconiosis. Here again it seems that it is the excess emphysema in the $p$ cases rather than any form of bronchitis associated with mucous gland enlargement which is responsible for the impairment of ventilation.

TABle IV-Disability in Coal Miners' Pneumoconiosis. Mean Values of Observations by Final $X$-ray Type

\begin{tabular}{c|c|c|c|c|c|c}
\hline $\begin{array}{c}\text { Final } X \text {-ray } \\
\text { Type }\end{array}$ & $\begin{array}{c}\text { Mean } \\
\text { Age in } \\
\text { Years }\end{array}$ & $\begin{array}{c}\text { Mean } \\
\text { FEV } \\
(1 .)\end{array}$ & $\begin{array}{c}\text { Mean } \\
\text { FVC } \\
(1 .)\end{array}$ & $\begin{array}{c}\text { Mean } \\
\text { FEV/FVC } \\
(\%)\end{array}$ & $\begin{array}{c}\text { Mean } \\
\text { Emphy- } \\
\text { sema } \\
\text { Count }\end{array}$ & $\begin{array}{c}\text { Mean } \\
\text { Reid } \\
\text { Index }\end{array}$ \\
\hline p & 63.5 & 1.50 & $2 \cdot 61$ & $57 \cdot 2$ & $15 \cdot 8$ & 44.3 \\
n & $62 \cdot 2$ & 2.03 & 3.08 & 65.1 & 7.1 & 43.0 \\
$\begin{array}{c}\text { Others and } \\
\text { not read }\end{array}$ & $61 \cdot 1$ & 1.76 & 2.73 & 64.2 & 7.8 & 44.2 \\
& 63.1 & 1.47 & 2.57 & 55.9 & 11.5 & 44.5 \\
\hline
\end{tabular}

Fig. 2 shows that there is a strong correlation between final $\mathrm{FEV}_{1}$ and emphysema whereas there is only a slight non-significant correlation between FEV, and Reid index. Fig. 3 shows similar findings in respect of $\mathrm{FEV} / \mathrm{FVC} \%$.

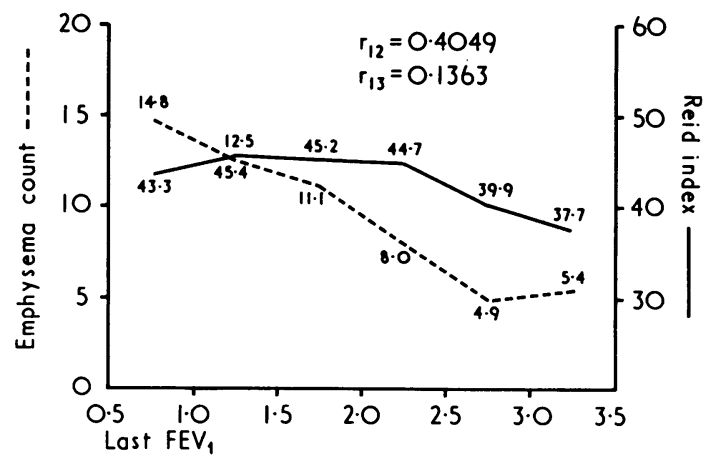

FIG. 2-Simple pneumoconiosis cases only. Correlation between final $\mathrm{FEV}_{1}$ and emphysema.

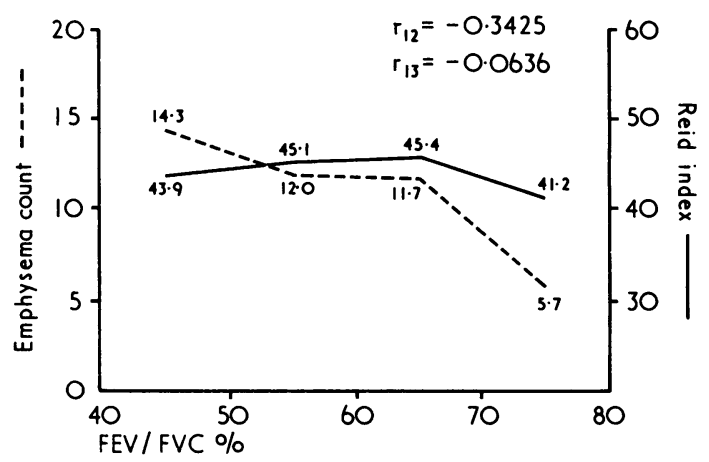

FIG. 3-Simple pneumoconiosis cases only. Correlation between FEV/FVC\% and emphysema.

Figs. 4 and 5 show the decline in $\mathrm{FEV}_{1}$ per annum in the years preceding the final examination according to $x$-ray category and type. The average period of serial observation of the FEV ranged from 4.6 years in category 1 to 5.7 years in categories $B$ and C. In these figures the normal rate of decline in FEV per annum is considered to lie between the figure of 0.034 litre given by Cotes (1965) and 0.038 litre given by Higgins and Oldham (1962).

Fig. 6 shows the average interval between the final examination and death according to radiological category; $19 \%$ were seen within a year of death, $45 \%$ within two years, and $77 \%$ within 


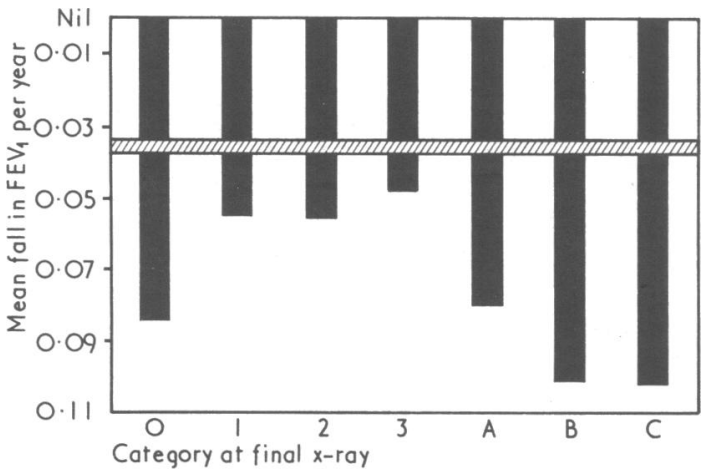

FIG. 4-Decline in $\mathrm{FEV}_{1}$ per annum according to final radiological category. Horizontal shaded line $=$ normal value.

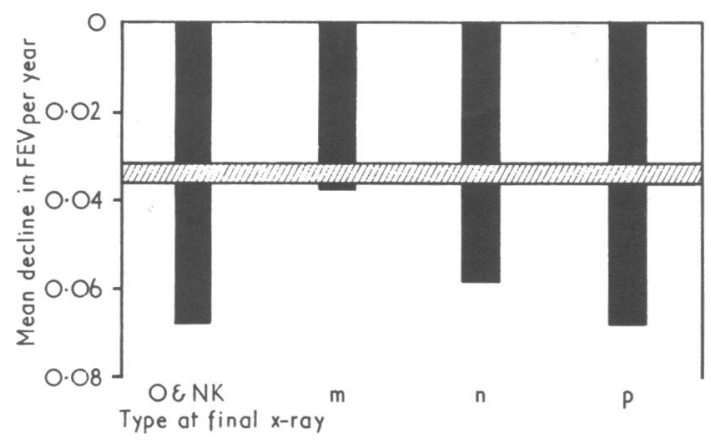

FIG. 5-Simple pneumoconiosis cases only. Decline in FEV per annum according to final radiological type. Horizontal shaded line $=$ normal values.

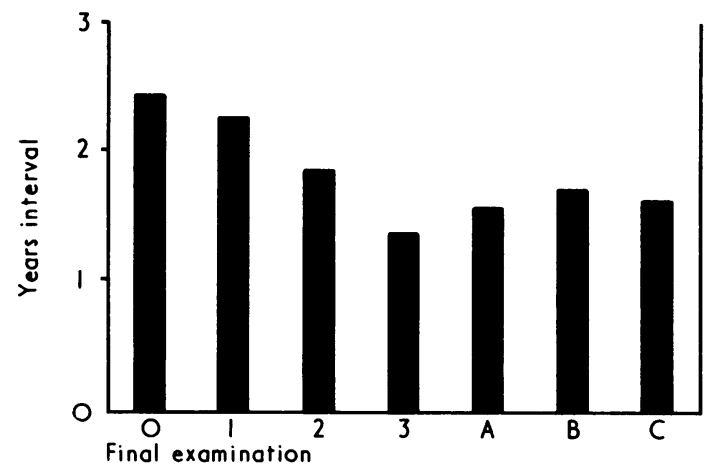

FIG. 6-Interval between final examination and death according to radiological category.

three years. In some of the cases the final lung function tests were carried out a comparatively short time before death; nevertheless these men in common with the remainder were sufficiently mobile to attend the Pneumoconiosis Medical Panel in Cardiff, usually by public transport, for the final examination and cannot, therefore, be considered to be terminal cases at the time of their last ventilatory capacity tests. Also in over $70 \%$ of cases pneumoconiosis was not considered to have caused or materially accelerated death.

Figs. 7 and 8 illustrate the influence of smoking on the $\mathrm{FEV}_{1}$ of patients in terms of final and serial values. The non-smokers and ex-smokers of more than eight years' standing with simple pneumoconiosis are less disabled in both respects than the smokers, but there is little difference between the smoking and non-smoking groups with complicated pneumoconiosis in terms of decline of FEV per year. Overall it would seem that the effects of smoking are not as prominent as might have been expected.

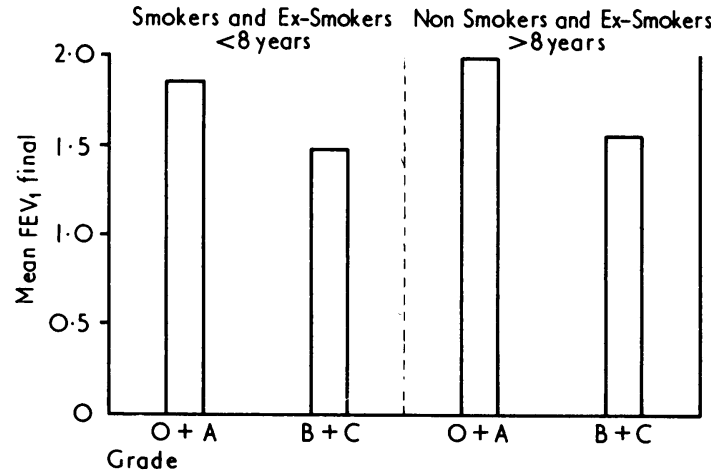

FIG. 7-Influence of smoking on final $\mathrm{FEV}_{1}$.

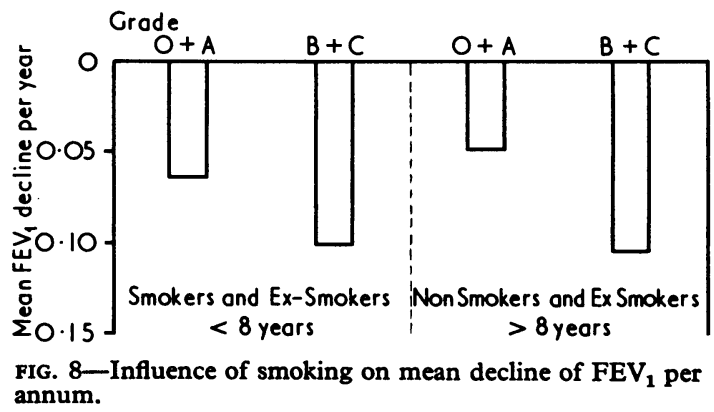

\section{Discussion}

Since the cases in our survey have been selected by death, we acknowledge that this may introduce biases in favour of increased morbidity and disability, as is inevitable in morbid anatomical studies of diseases which may prematurely cause or accelerate death. However, we have already given reasons (Ryder et al., 1970a, 1970c) why we believe the operation of such biases to be minimal in our miners. Also as all the miners had attended the Pneumoconiosis Medical Panel the results might not be applicable to pneumoconiosis cases in general in the area if there were good reasons to believe that a substantial number of cases existed which were unknown to the Panel. Here again we have already shown by utilizing findings from the N.C.B. periodic $x$-ray scheme that most coal miners with compensatable pneumoconiosis-that is, category 2 and upwards-in the relevant area are known to the Panel and for these reasons we believe that the pattern, though not necessarily the degree, of ventilatory impairment in our miners is typical of compensatable coal workers' pneumoconiosis in the area covered by the survey. On the other hand, unequivocal category 0 and category 1 cases are not normally advised to apply to the Panel, particularly if they are asymptomatic, and since it seems probable that many of our cases in these categories have been selected by respiratory symptoms, they cannot be considered to be similarly representative.

Subject to these reservations we draw the following broad conclusions: (1) coal workers' pneumoconiosis usually caused progressive impairment of ventilation which was not related to radiological category in the simple form of the disease; $(2)$ the presence of emphysema accompanying simple pneumoconiosis was a more important factor in determining the impairment of ventilation than the radiological category; and (3) the Reid index was not significantly related to either emphysema or impairment of ventilation.

It is clear from Tables I and II and from Fig. 1 that all aspects of ventilation were affected to some degree in all radiological categories of pneumoconiosis, the overall picture being obstructive in character. Disability, however, was slight and difficult to detect without serial observations in many cases. 
Fig. 4 shows that a decline in $\mathrm{FEV}_{1}$ per annum in excess of normal was also present, and though this decline was less pronounced in category 3 it was none the less present in all categories. These findings taken overall do not support the conclusions either that simple pneumoconiosis does not of itself cause disablement or that radiological progression in pneumoconiosis would not be accompanied by a significant impairment of FEV until the changes amounted to category $B$ progressive massive fibrosis. Such conclusions which were arrived at by Carpenter et al. (1956) and Cochrane et al. (1961) from their Rhondda studies might reasonably be deduced from the physiological evidence available to them, which consisted of a single ventilatory capacity iest. However, their cases of simple pneumoconiosis, though less disabled than ours, did show definite impairment of ventilation. They concluded that this was probably not due to pneumoconiosis because it was not related to radiological category, but they were unable to account for it satisfactorily. We suggest that emphysema undetectable radiologically is responsible for the impairment of ventilation in such cases.

Bronchitis, of course, may well play some part also in the symptomatology of our cases although it would seem that chronic bronchitis in the sense of an excess mucus-secreting disease, evidenced pathologically by a positive Reid index, plays little part in determining the disability in them. We have already shown that there was no significant difference between our miners and a contrast non-mining population in terms of a raised Reid index (Ryder et al., 1972), and Figs. 2 and 3 indicate that the Reid index was not significantly related to either emphysema or impairment of ventilation. Table IV, which shows the relation between the type of pneumoconiosis, the emphysema count, and the Reid index, indicates that there is no increase in the Reid index among the $p$ cases although these cases have an increased incidence of emphysema and are more disabled than the other radiological types.

The precise nature of the emphysema and its relation to pneumoconiosis cannot always be determined even at necropsy, particularly if the changes are advanced. A definite relation has been postulated, however, in view of the considerable excess of emphysema in the pneumoconiosis cases compared with the contrast population previously demonstrated, and also because the changes most nearly resemble the appearances described and illustrated by Gough (1968) of stellate dust nodules with surrounding perifocal emphysema which in many cases had proceeded to a destructive and indeterminate stage. This was particularly true of the $p$ cases and it may well be that the stellate type of dust focus (in which collagenous changes may be present) accounts for the reticular and irregular, often cystic, appearances sometimes present in the $x$-ray film.

In some cases where the stellate foci are connected to one another by dust-impregnated fibrosis, as may often be the case, the appearances resemble and might be regarded as a form of interstitial fibrosis. In view of the fact, however, that these interstitial fibrotic changes are related primarily to the respiratory bronchioles rather than to the more peripheral alveoli, it becomes a matter of semantics whether this may be regarded as a true variety of interstitial fibrosis.

Whatever the pathogenesis of the changes in these cases may be, the condition of the lung parenchyma between the actual nodules must be an important factor in determining disability. As this cannot be visualized radiographically, particularly by estimation of the nodular changes alone, the old International Labour Office, Geneva (1958) Classification may not always be a reliable guide to the extent of the pathological changes and consequently the disability. Some of the category 0 and category 1 cases in the present survey illustrate this fact.

As we have already pointed out (Ryder et al., 1970a, 1970c), a few of the category 0 cases had radiological changes which were not considered to represent pneumoconiosis by most of the observers and an alternative diagnosis was preferred, this being emphysema in four cases and fibrosing alveolitis in three cases. All of these showed a comparatively substantial degree of pneumoconiosis usually with extensive emphysema at necropsy and several of the cases labelled category 1 or category 1 plus emphysema had similar pathological findings.

We are not suggesting that significant pneumoconiosis may exist without radiological changes but rather that the emphasis on nodulation under the old classification may be overstressed at the expense of linear, irregular, and cystic-type opacities which may also be due to pneumoconiosis. We feel that this should be more widely known, especially when it is considered that emphysema is more likely to be present in cases showing these types of change in addition to nodulation. It may well be that the new Extended Classification of Radiographs of Pneumoconiosis (Revised, 1968) issued by the International Labour Office, Geneva, which does cater for irregular opacities in addition to the purely nodular ones may prove more useful in coal workers' pneumoconiosis than the earlier one.

We are indebted to Dr. J. Watkins-Pitchford, Chief Medical Adviser, Department of Health and Social Security, for permission to use the Panel material; to those senior medical officers who read the $x$-ray films; and to Miss C. Squance, Cardiff P.M.P., for valuable secretarial help.

\section{References}

Carpenter, R. G., Cochrane, A. L., Gilson, J. C., and Higgins, I. T. T. (1956). British fournal of Industrial Medicine, 13, 166

Cochrane, A. L., Moore, F., and Thomas, J. (1961). Tubercle, 42, 64.

Cotes, J. E. (1965). Lung Function, p. 374. Oxford, Blackwell Scientific.

Cotes, J. E., Deivanayagam, C. N., Field, G. B., and Billet, L. (1970). In British Occupational Hygiene Society. Proceedings of the Third International Symposium on Inhaled Particles, London, Unwin Bros.

Englert, M., and De Coster, A. (1965). Fournal Fransais de Médicine et Chirurgie Thoraciques, 19, 159.

Gilson, J. C., and Hugh Jones, P. (1955). Medical Research Council. Special Report Series, No. 290. London, H.M.S.O.

Gough, J. (1968), The Lung, p. 111. Baltimore, Williams and Wilkins.

Higgins, I. T. T., and Oldham, P. D. (1962). British fournal of Industrial Medicine, 19,65 .

Medicine, 19, 65.
Lyons, J. P., Clarke, W. G., Hall, A. M., and Cotes, J. E. (1967). British Medical fournal, 4, 772. McKerrow, C.B., McDermott, M, and Gilson, J.C. (1960). Lancet, 1, 149.
Morgan, W. K. C., Burgess, D. B., LeRoy Lapp, N., and Seaton, A. (1971). Thorax, 26, 585 .

Rasmussen, D. L., and Nelson, C. W. (1971). American Review of Respiratory Disease, 103, 240.

Reid, L. (1958). Recent Trends in Chronic Bronchitis, ed. N. C. Oswald, p. 26. London, Lloyd Luke.

Rogan, J. M., et al. (1961). British Medical fournal, 1, 1337.

Ryder, R., Lyons, J. P., Campbell, H., and Gough, J. (1970a). British Medical fournal, 3, 481.

Ryder, R., Lyons, J. P., Campbell, H., and Gough, J. (1970b). British Medical fournal, 4, 305 .

Ryder, R., Lyons, J.' P., Campbell, H., and Gough J. (1970c). British Medical fournal, 4, 623.

Ryder, R., Lyons, J. P., Campbell, H., and Gough, J. (1972). Proceedings of the International Conference on Coalworkers' Pneumonconiosis, New or the International
York. In press. 